\title{
DESIGN OF PEDAL OPERATED WHEEL DRIVE FORKLIFT
}

\author{
Aditya Vaidya, Krunal Rotliwala, Mahesh Prajapati, Nikunj Patel, Rahul Rajpurohit \\ Mechanical Engineering Department, Final Year Students FETR, \\ Bardoli-Surat, Gujarat, India \\ Mitul Patel \\ Assistant Professor, Mechanical Engineering Department, FETR, Gujarat, India \\ Faculty of Engineering Technology and Research, Isroli, Bardoli \\ Department of Mechanical Engineering, India
}

\begin{abstract}
Mechanical fork lift is an improved and advance technology that helps brought about revolution in the mechanical industries today all heavy engineering company uses it. Widespread use of the forklift truck had revolutionized warehousing practices before the middle of the 20th century. A mixture of material handling systems is in the use, exact from that entirely physical to the ones that are semi-automatic but manually controlled. Forklifts have revolutionized warehouse work. They made it possible for one person to move thousands of pounds at once. Well-maintained and safely operated forklifts make lifting and transporting cargo infinitely easier. This is the general description of a normal forklift truck. In Institutes or Colleges small goods cannot moved around easily by any human body, so to fill this need we have propose a Pedal Operated forklift (electrical operated) to lift and transport such medium weight goods. It is a fast, efficient and low power consumption vehicle that does not require much space to move around.
\end{abstract}

Key words: FORK, FORKLIFT, SEGWAY.

Cite this Article: Aditya Vaidya, Krunal Rotliwala, Mahesh Prajapati, Nikunj Patel, Rahul Rajpurohit and Mitul Patel, Design of Pedal Operated Wheel Drive Forklift. International Journal of Design and Manufacturing Technology (IJDMT), 9(1), 2018, pp. 17-22.

https://iaeme.com/Home/issue/IJDMT?Volume=9\&Issue $=1$

\section{INTRODUCTION}

This article guides a stepwise walkthrough of Forklift and its related Technology.Forklift is a device which is used to transfer goods from origin to destination point. Running on fuel (diesel mostly) they can generate required torque for defined applications. Segways are short distance transport domestic vehicle which are mostly used in malls and domestic transportation. 


\section{OBJECTIVES}

- To modify mechanism of forklifts.

- Using two wheel drive forklift to simplify driving experience.

- To make effective loading/ unloading of object using latest robot techniques.

- To make operations environment friendly.

- To reduce cost of operation by substituting fossil fuel engine.

- Increase safety at work.

- Increase accuracy of work.

- Automation of application.

\section{PROCEDURE}

\subsection{Bits and Pieces Together}

We've taken references by analyzing needs of workers from our institute. By analyzing their need we`ve thought to combine various technologies like Forklift\& Segway. By combining these technologies we can ease the workload of workers and maximize their capacity to lifting and transferring their goods effectively. After these thought we've started analyzing required Data to Design and Manufacture our two wheeldrive forklift. We've taken references from some international journals containing research and data of 'Fork, Forklift and Segway'. All the References for Designing 'Two Wheeldrive Forklift' are taken from respective data books and research papers.

\subsection{Use of Simulation Software}

There was numbers of software available which can mimic the process involved in our research work and can produce the possible result. One of such type of software was CREO parametric. We can easily make design and modeling of our desired product in 3-D. Second of such type of software was Ansys, in which we can analyses the load applying on product and find it is safe or not. We can also use other software like AUTOCAD, Top Solid, and MATLAB for modeling and performing Static Load Analysis on our product.

\section{IDENTIFY, RESEARCH AND COLLECTED IDEA}

We've analyzed the Data available from already researched Journals on our subject, through the Internet. We've also analyzed Standard Design book for Manufacturing of Forklift. After Analyzing all the data we've found that our design is viable and safe. After Exploring of new possibilities in forklift technology, we've tried to apply to our design. After some Corrections and Modification we found the new way to apply these technologies feasibly. All these technologies were helpful to make our forklift better and ease in use.

Picture of Analysis and Components are Given Below: 
Design of Pedal Operated Wheel Drive Forklift

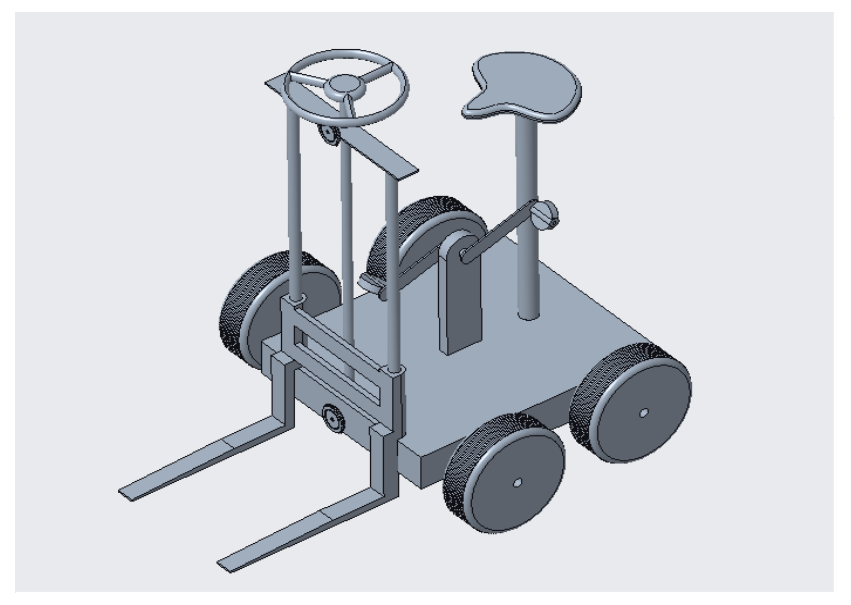

Figure 1 Two Wheeldrive Forklift

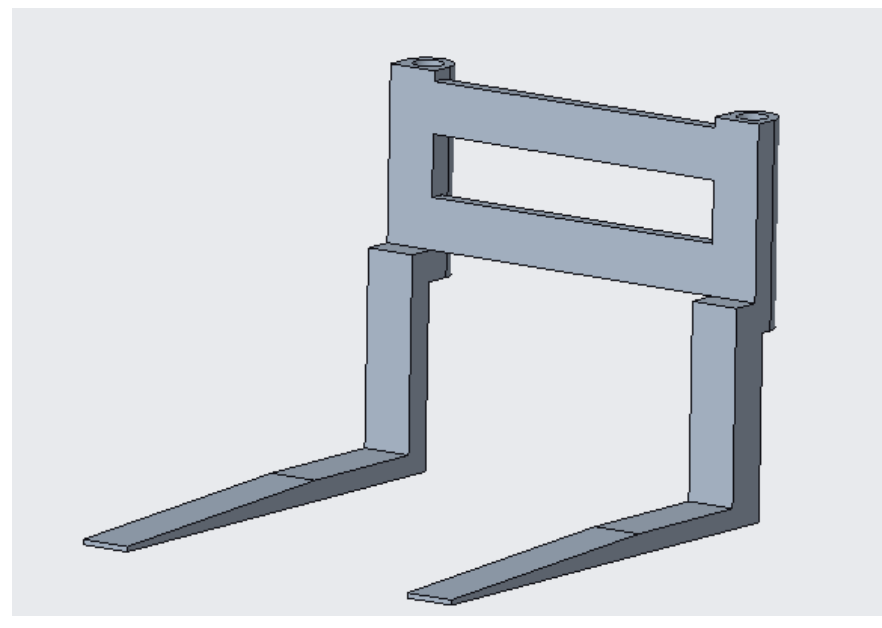

Figure 2 Fork

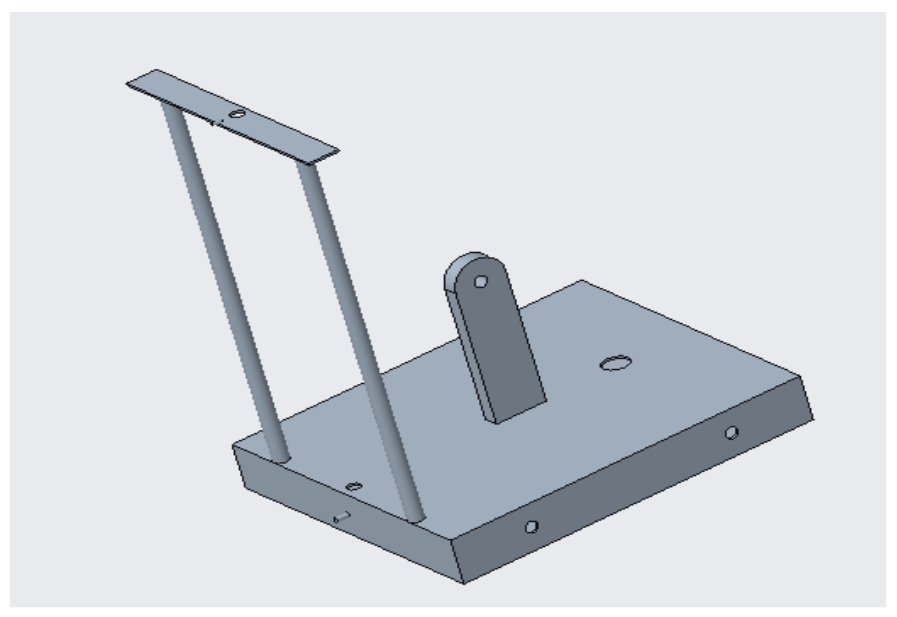

Figure 3 Base of Two wheeldrive Forklift 
All dimensions are in $\mathrm{mm}$

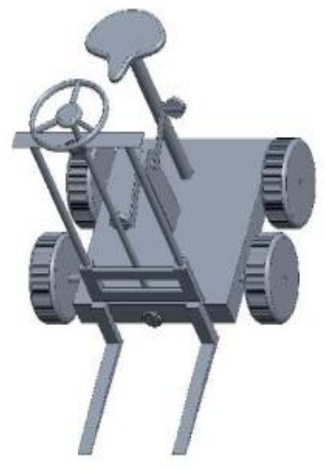

3-D View

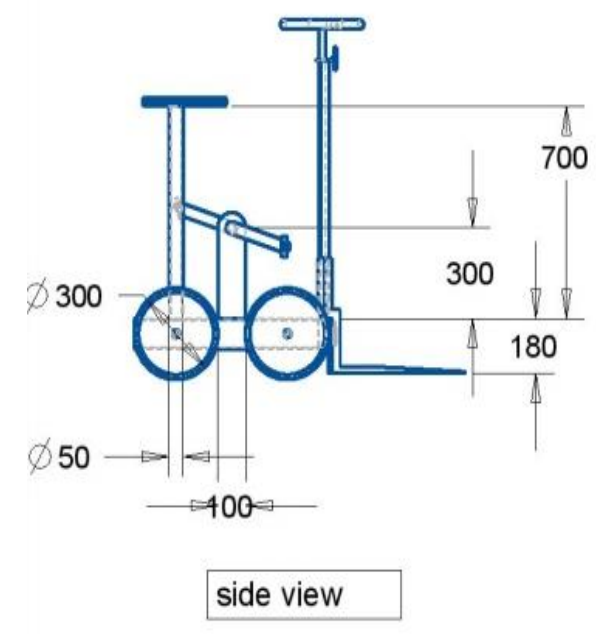

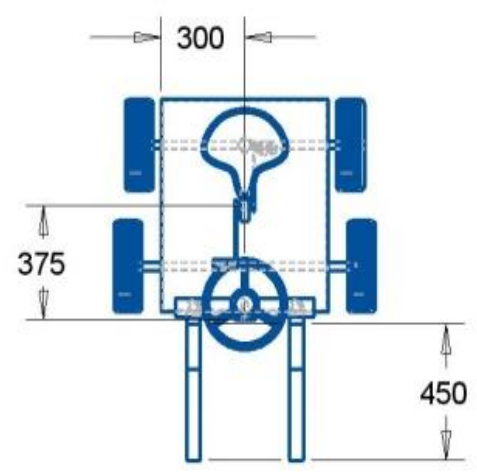

Top View

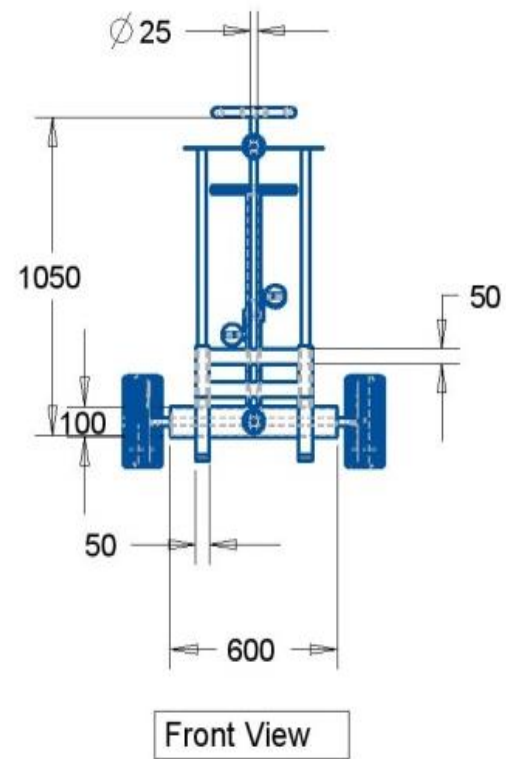

Figure 4 Dimensions and Views of Forklift

\section{IMPROVEMENT AS PER REVIEWER COMMENTS}

Importance to Feedback and Reviews are given. As per feedback and replies we got from our Volunteers, we`ve made certain changes in Our Design.

- Pedal Mechanism is provided to reduce cost.

- Chain Drive is used instead of Belt drive to make operation safe and reduce slip.

- Steering Mechanism is improved.

- Design of Fork Attachment has been improved. 


\section{CONCLUSIONS}

We can conclude that with using our 'Two Wheeldrive Forklift' any worker working in institute or warehouse can effectively Load/ Unload/ Transfer material. Efficiency of material handling capacity will be higher compared to bare hands. There will be less Physical Problem, Specially the 'Spine Problem. Effectiveness and easiness of Certain Operations will be Maintained Easily.

\section{ACKONWLEDGEMENT}

I express my deep sense of gratitude to my project supervisor Prof. MITUL D. PATEL, Assistant Professor, Department of Mechanical Engineering for providing precious guidance, inspiring discussions and constant supervision throughout the course of this work. His timely help, constructive criticism efforts made it possible to present the work contained in this thesis. I am deeply indebted to my parents for their inspiration and ever encouraging moral support, which enabled me to pursue my studies. I am also thankful to my friends and wellwishers, for their constant support which help me in successful completion of the dissertation work.

\section{REFERENCES}

[1] 3-D Research on Forkarms of Forklift Trucks by University of Polytechnica of bucharest, machine and manufacturing department, bucharest, Romania.

[2] Design, Fe analysis \& Optimization of Forktrucks lifts of Automated Guided Vehicle by Shailesh Bhanushali, SPB engineering college, Mehsana, Gujarat, India. (IJRMEET)ISSN:2320-6586

[3] Dynamic Analysis of Forklift During Load lifting using Modeling and Stimulation by International Journal of current engineering and Technology (ISSN:22774106), June-2013

[4] Design Development and Modeling of Forklift by International Journal of Engineering and Research\& Technology (ISSN:2278-0181), April-2014

[5] Static Analysis of Forklift by West virginia University Institute of Technology (WVU tech) West virginia 25136, USA. Proceeding of 2015 ASEE north central conference.

[6] Design and Analysis of Forklift by Supreeth narsimhamurti, university of washington1327291

[7] Design and Fabricated Pneumatic operated forklift by Int. J. Engg. Res. \& Sci. \& Tech. 2015, ISSN 2319-5991

[8] Design Modification and Analysis of Automobile wheel Rim Using Finite Element Analysis, ISSN-2321-0613

[9] Dynamic Analysis of Forklift During Load lifting using Modeling and Stimulation by International Journal of current engineering and Technology (ISSN:22774106), June-2013 


\section{ABOUT AUTHORS}

First Author. Aditya Vaidya, Mechanical Eng. Dept; FETR, Bardoli mailto:smartadi85@gmail.com

Second Author. Krunal Rotliwala, Mechanical Eng. Dept; FETR, Bardoli mailto:rotliwalakrunal@gmail.com

Third Author. Mahesh Prajapati, Mechanical Eng. Dept; FETR, Bardoli mailto:mkp.mechanical102@gmail.com

Fourth Author. Nikunj Patel, Mechanical Eng. Dept; FETR, Bardoli mailto:patelnikunj9909@gmail.com

Fifth Author. Rahul Rajpurohit, Mechanical Eng. Dept; FETR, Bardoli mailto:rahulrajpurohit610@gmail.com

\section{STANDARDS TAKEN IN DESIGN}

ANSI B56:-Industrial Truck Standard Development and Foundation (ITSDF).

Safety Standard:-29CFR1910.178

OSHA (Occupational Safety and Health Administration) in US

HSE (Health and Safety Executive) in UK.

\section{Rule for Counter weight:}

Counter weight must be $1.5 x$ more than loading material weight. 